\title{
Effect of Eleutherine americana Merr. bulb extract on blood pressure and heart rate in anesthetized hypertensive rats
}

\author{
Yori Yuliandra ${ }^{*}$, Rizki Oktarini, \& Armenia \\ Faculty of Pharmacy, Andalas University, Indonesia
}

\begin{abstract}
The effect of ethanolic extract of Eleutherine americana Merr. on the blood pressure and heart rate has been investigated. A number of 25 Sprague-Dawley male rats were induced with prednisone $1.5 \mathrm{mg} / \mathrm{kg}$ in combination with saline solution $2.5 \%$ for 14 days to obtain hypertension model. The rats were anesthetized and prepared for the recording of blood pressure and heart rate. The rats were divided into five groups receiving 100, 200, and $400 \mathrm{mg} / \mathrm{kg}$ of the extract, vehicle control, and captopril $30 \mathrm{mg} / \mathrm{kg}$ as the reference. The treatment was administered three times with 30 minutes interval. The systolic (SBP), diastolic (DBP), mean arterial pressure (MAP), and heart rate (HR) were recorded. The data were analyzed with two-way analysis of variance (ANOVA) followed by Duncan's MRT (95\% confidence interval). The study revealed that the extract exhibited a blood pressure lowering effect. The best antihypertensive activity of the extract was shown by the dose of $100 \mathrm{mg} / \mathrm{kg}$. Meanwhile, HR was also affected inversely by the treatment, in which the lowest dose caused the highest increase. The study suggests that the extract of Eleutherine americana exhibits antihypertensive activity that may be potential for future development of drugs.
\end{abstract}

Kata kunci: eleutherine americana; extract; hypertension; blood pressure; heart rate.

\section{Introduction}

The use of herbal medicines in the prevention and treatment of diseases has long been implemented by our ancestors since the dawn of medicine. This empirical effort has contributed to the discovery of synthetic drugs started in the nineteenth century. This advance has brought the medicine to an era of synthetic drugs dominated by pharmaceutical companies, marked by a concept of monodrug therapy and less interest to use natural products. However, the World Health Organization (WHO) has announced that at least $70 \%$ of the world's population count on traditional medicines for primary healthcare [1]. In addition, the interest in bringing traditional medicines into practices is growing rapidly across countries. These include the use of plants extracts along with their chemical constituents. Therefore, herbal medicines remain to play a significant role in the era of modern medicine $[2,3]$.

One of the natural products that have gained much interest is Eleutherine americana Merr. Having been used traditionally in the treatment of many diseases, e.g. cancer and cardiovascular diseases, this medicinal plant is considered promising for future development of drugs. Many researchers have investigated not only pharmacological activities of the plant but also its chemical constituents that might be responsible for the therapeutic effect. Some major compounds that have been successfully isolated are classified to three big groups: naphthalene, anthraquinone and naphthoquinone [4-6]. The pharmacological activities of extracts and chemical constituents derived from the bulb of the plant include antimicrobial, anti-inflammatory, antidiabetic, and cytotoxic [7].

In the cardiovascular system, E. americana has been reported to exhibit vasodepressant properties. In addition, the chemical compound in this plant is also capable of increasing the coronary flow in the heart of guinea pig $[8,9]$. More recently, a report from Indonesia suggested that the extract of the plant shows the blood pressure lowering effect in hypertensive rats induced by fructose with a marked increase in urine production [10]. However, there is no further report on whether the extract also exhibits antihypertensive activity in other models of hypertension. The objective of the present study was to investigate the blood pressure lowering effect of E. americana extract in the hypertensive rats induced by prednisone and salt.

*Corresponding Author: Yori Yuliandra Department of Pharmacology \& Clinical Pharmacy, Faculty of Pharmacy, Andalas University Campus Limau Manis, Pauh, Padang 25163, Indonesia| Email: yoriyuliandra@phar.unand.ac.id
Access this article

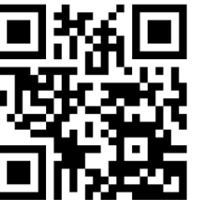


The finding of the study was expected to provide more data on the possible pharmacological activities of the plant for the future development of the plant for pharmaceutical purposes.

\section{Methods}

Drug and chemicals

Prednisone and captopril were obtained from a local pharmacy. Propofol (Fresofol ${ }^{\circledR}$ ) was a product of PT Fresenius Kabi (Jakarta, Indonesia). Heparin and $\mathrm{NaCl}$ $0.9 \%$ intravenous infusion were products of BBraun (Jakarta, Indonesia). Ethanol 70\% and distilled water were purchased from Bratachem (Brataco PT, Indonesia). All materials were used as received.

Extract preparation

Eleutherine americana Merr plants were obtained from Padang City, West Sumatra, Indonesia and identified in Herbarium of Andalas University (ANDA). About 500 $\mathrm{g}$ of the shade-dried bulb of the sample was powdered and extracted with ethanol by maceration method. The extraction was conducted three times and considered complete when the macerate gradually turned colorless. The solvent extract was concentrated by a rotary evaporator. The extract underwent the preliminary phytochemical test.

Animal preparation

A number of 25 adult male Sprague-Dawley rats (weighed $\pm 250 \mathrm{~g}$ and aged 3-4 months old) were acclimatized to normal laboratory condition. Standard chow and water ad libitum were provided. The animals were induced with prednisone $1.5 \mathrm{mg} / \mathrm{kg}$ in combination with $2.5 \%$ salt solution for 14 days. Hypertension was indicated if the mean arterial pressure was above $150 \mathrm{mmHg}$ [11]. All protocols of the experiment were approved by the ethics committee of the Faculty of Medicine, Andalas University (152/KEP/FK/2018).

\section{Antihypertensive activity evaluation}

The rats received propofol $150 \mathrm{mg} / \mathrm{kg}$ intraperitoneally to induce sedation for anesthetized blood pressure monitoring. The direct measurement of the blood pressure was conducted through the carotid artery by using arterial cannula connected to a pressure transducer and hemodynamic recorder (Biopac MP 150, USA). The left jugular vein was prepared for saline-heparin and supplementary infusion of propofol $4 \%$ infusion by using PP 50 tubing. The rats were divided into five groups receiving vehicle control; extract 100, 200, and $400 \mathrm{mg} / \mathrm{kg}$; and captopril $30 \mathrm{mg} / \mathrm{kg}$ as the reference. The treatment was administered three times with 30 minutes interval. The systolic blood pressure (SBP), diastolic blood pressure (DBP), mean arterial pressure (MAP) and heart rate (HR) were recorded for further analysis [12].

\section{Data Analysis}

Data were presented as the mean of percent change \pm standard deviation (SD). The data were analyzed by using two-way analysis of variance (ANOVA). Significant differences were followed by Duncan's MRT (Multiple Range Test). The significance level was taken at 95\% confidence interval for all analyses

\section{Result dan Discussion}

The phytochemical and pharmacological properties of Eleutherine americana Merr. have gained more interest since the mid of the 1990s. This medicinal plant originated in tropical America are currently cultivated across the globe. In Indonesia, it is well known as "bawang dayak", representing the native tribe in Borneo island, the place where it has been widely cultivated. Along with the publication of popular articles over the internet claiming the benefit of consuming the herbs of this plant, extensive researches have reported its potential development for pharmaceutical purposes. These include its pharmacological activities against bacteria and virus, to reduce the inflammation, high blood sugar, and within the cardiovascular system [7].

Many reports on the pharmacological activities of $E$. americana in the cardiovascular system has been published. Among these, some may be potential to lower the high blood pressure such as reducing the tone of blood vessels and increasing the coronary flow [8,9]. The extract of this plant has also been reported to reduce the blood pressure of rats induced with high fructose, causing an increase in urine volume and improved cardiogram profile

Table 1. Preliminary test results of chemical constituents of E. americana extract

\begin{tabular}{|cc|}
\hline Compound groups & Results of examination \\
\hline Flavonoids & + \\
Alkaloids & + \\
Triterpenoids & + \\
Steroids & + \\
\hline
\end{tabular}




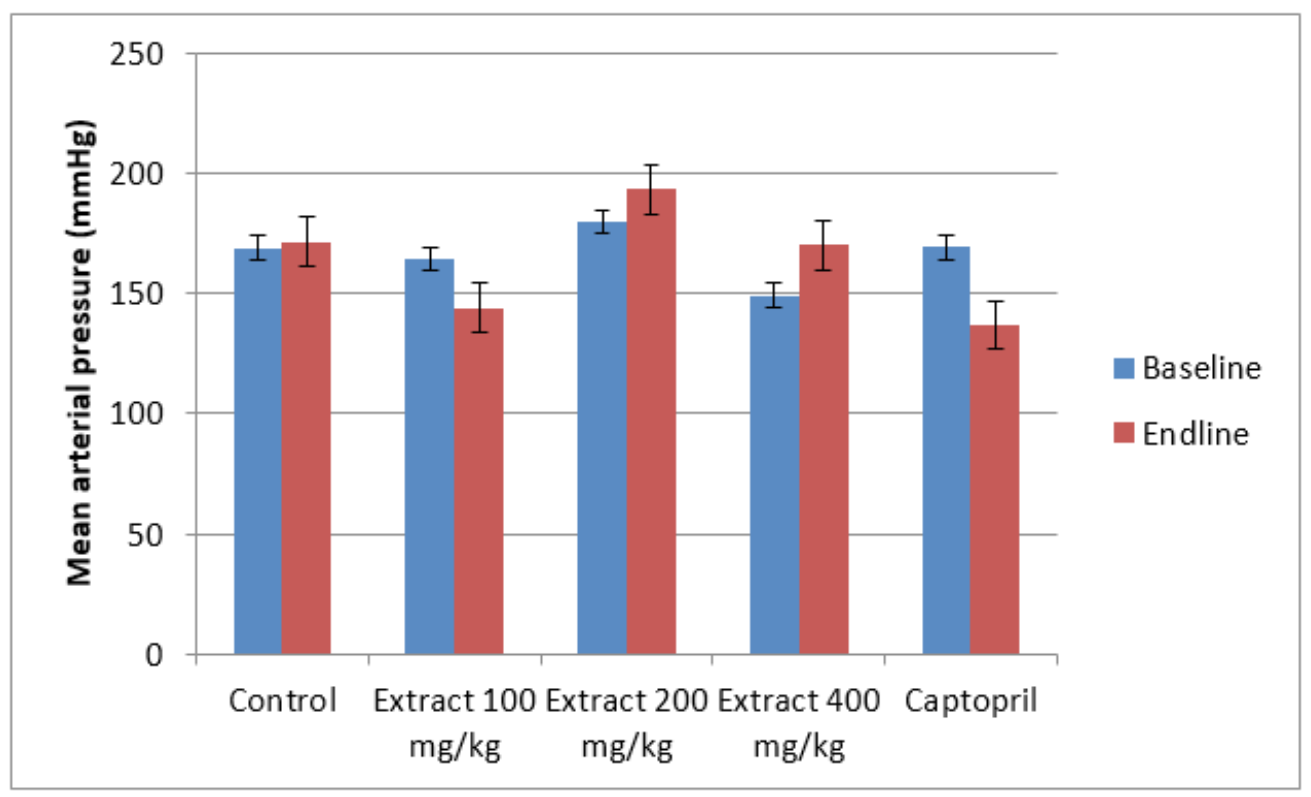

Figure 1. Comparative changes of mean arterial pressure due to the treatment of extract of Eleutherine americana

[10]. Although many reports have suggested the potential antihypertensive effect of the plant, the investigation of the effect on endocrine-related hypertension has not been reported to our knowledge. The present study was aimed to explore the blood pressure lowering activity of $E$. americana extract in prednisone-salt-induced hypertensive rats.

The preliminary qualitative determination on the extract contents of E. americana on the present study showed that the extract contained flavonoids, alkaloids, triterpenoids, and steroids (Table 1), confirming the finding of a previous study [10]. The present study did not further determine the chemical contents into a specific classification. Nevertheless, some major compound groups with interesting biological activities have been reported: naphthalene, anthraquinone and naphthoquinone. Some other compounds have also been isolated such as stigmasterol and kadsuric acid [5,7].

The main results of the present study showed that the extract significantly influenced the systolic, diastolic, and mean arterial pressure. Figure 1 roughly demonstrates the extent of blood pressure lowering effect of the extract to the mean arterial pressure (MAP) after three repetitive administration. Among three different doses tested, the

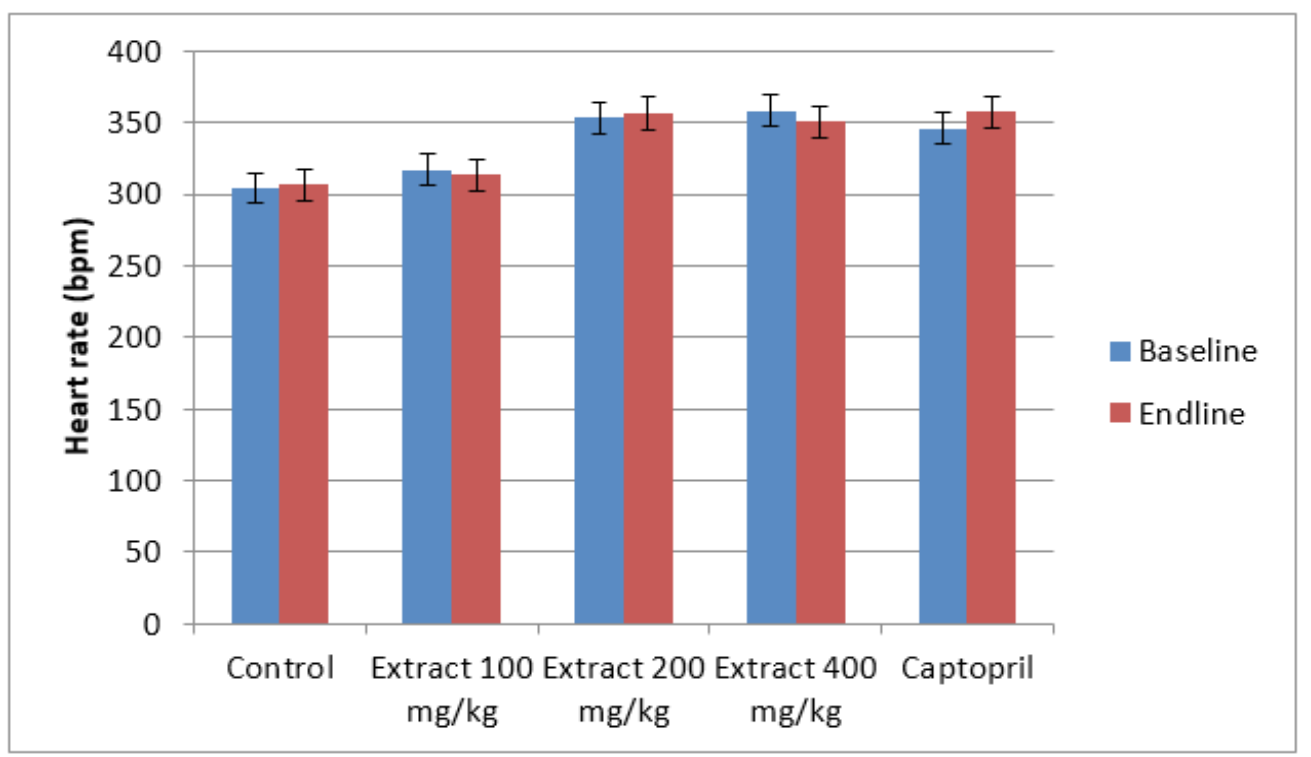

Figure 2. Comparative changes of heart rate due to the treatment of extract of Eleutherine americana 


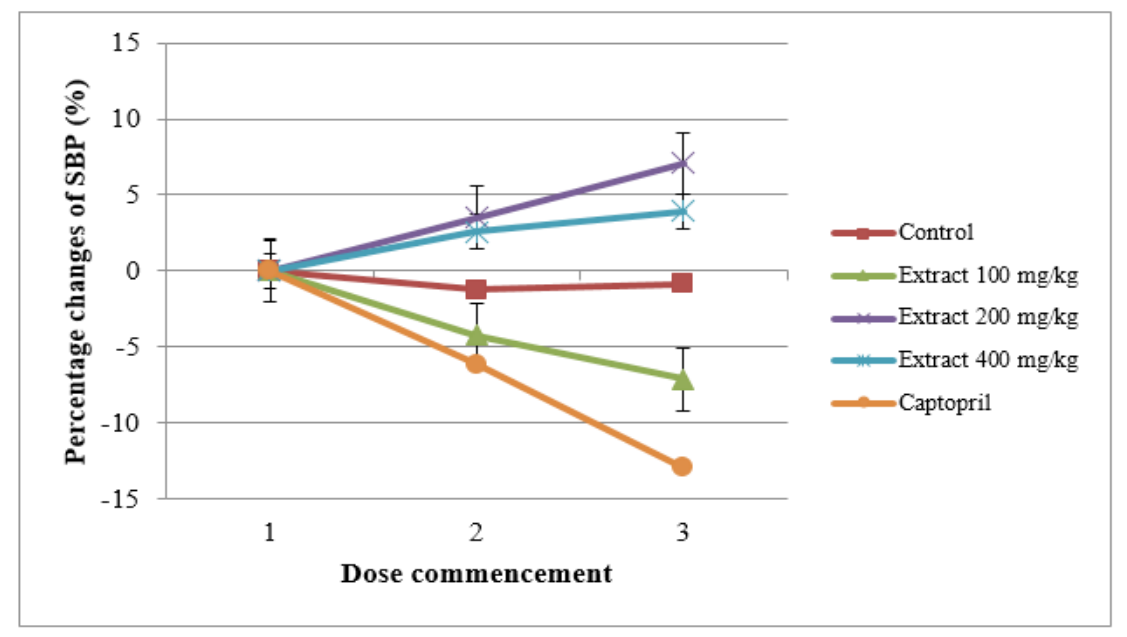

Figure 3. Comparative effect of intraperitoneal administration of extract of Eleutherine americana to the SBP (systolic blood pressure)

lowest dose $100 \mathrm{mg} / \mathrm{kg}$ exhibited better blood pressure lowering activity for SBP, DBP and MAP than larger doses. Interestingly, higher doses (200 and $400 \mathrm{mg} / \mathrm{kg}$ ) tent to possess contrary effect as compared with $100 \mathrm{mg} /$ $\mathrm{kg}$ dose and increased the blood pressure even higher than the control did. The study also showed that the effect of the extract to the blood pressure was not significantly different from that of captopril $(\mathrm{p}>0.05)$.

The extract also influenced the heart rate (HR) significantly $(\mathrm{p}<0.05)$. However, the lowest dose $100 \mathrm{mg} /$ $\mathrm{kg}$ demonstrated a higher increase of $\mathrm{HR}$ as compared with other extract doses (Figure 2). In contrast, the most elevated heart rate was shown by captopril. This phenomenon may be closely related to the theory of blood pressure calculation, in which the heart rate is affecting the blood pressure inversely [13]. A similar circumstance was also seen in most of our previous antihypertensive studies $[11,14,15]$.

Further examination on the effect of the extract to the systolic, diastolic, and mean arterial pressure and heart rate showed are demonstrated by Figure 3-5, showing that the extract at the dose of $100 \mathrm{mg} / \mathrm{kg}$ exhibits better blood pressure lowering effect as compared with other doses. Meanwhile, Figure 6 illustrates different trend which is previously mentioned.

The measurement of the blood pressure was undertaken through the cannulation of the carotid arteryknown as the direct method. Some of our previous

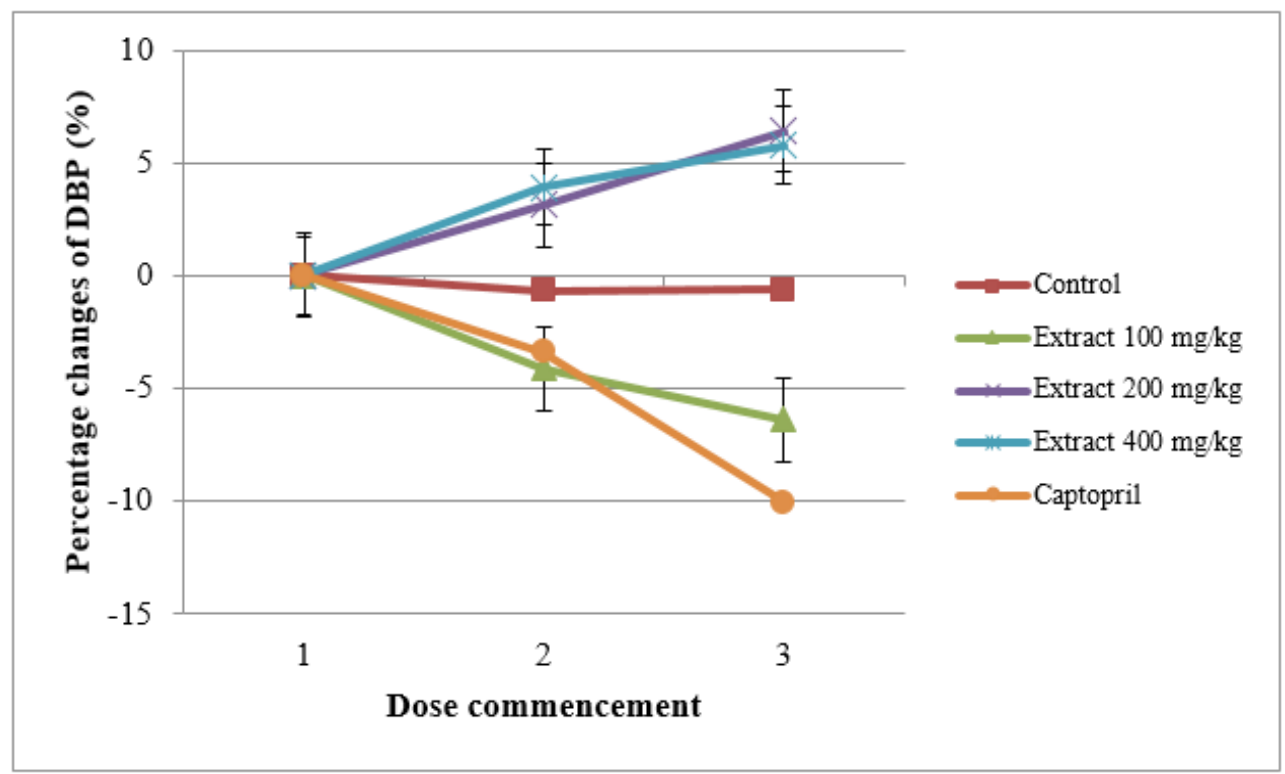

Figure 4. Comparative effect of intraperitoneal administration of extract of Eleutherine americana to the DBP (diastolic blood pressure) 


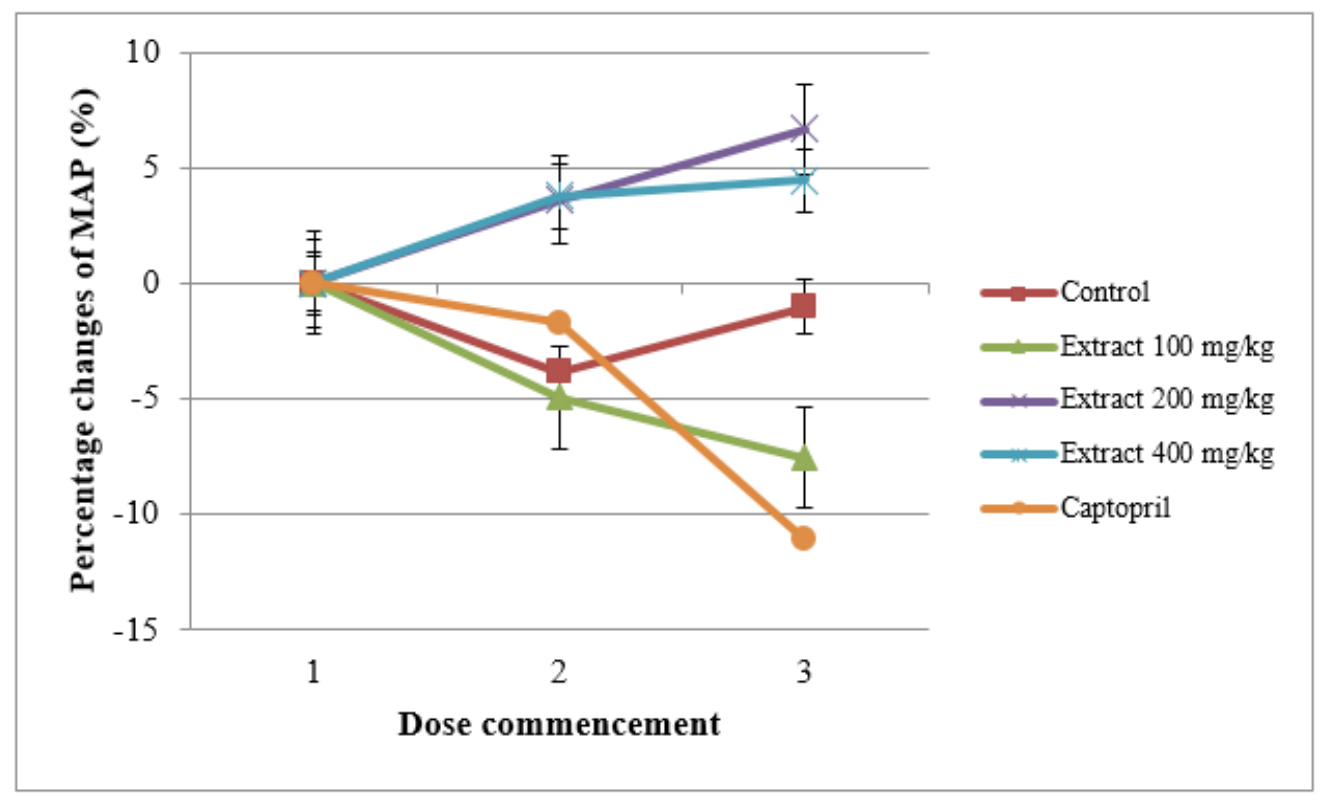

Figure 5. Comparative effect of intraperitoneal administration of extract of Eleutherine americana to the MAP (mean arterial pressure)

studies have suggested that this method were capable of coping the whole techniques used in the study, including the use of prednisone and salt as inducers to obtain experimental animals with elevated blood pressure [11,15]. In addition, despite invasive and requires some minor surgical procedures, the direct method in measuring blood pressure is considered as a gold standard for this purpose [16]. This includes the preliminary study of plants extract to investigate their potential blood pressure lowering activity [17].

Although a previous study has suggested that the ethanol extract of E. americana exhibited antihypertensive activity [10], the present study provides its own significance to support the blood pressure lowering effect of the extract due to the use of different inducer of hypertension, thus different type of hypertension. It has been suggested that using some different animal models is necessary for the evaluation of a potential agent or plant extract. This

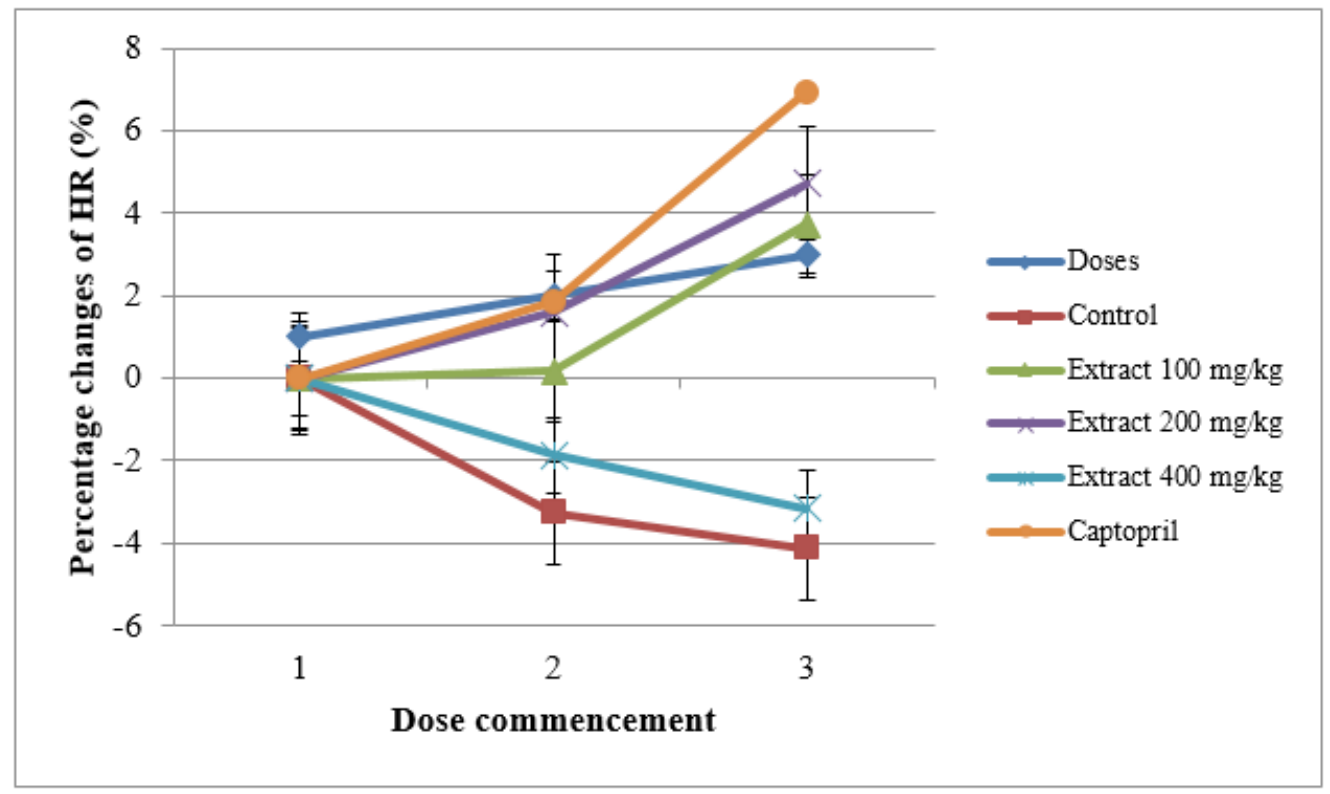

Figure 6. Comparative effect of intraperitoneal administration of extract of Eleutherine americana to the HR (heart rate) 
is due to the complexity of human hypertension which is sometimes considered multifactorial [18]. In addition, the disease of elevated blood pressure itself is divided into essential and secondary hypertension where each of them is likely to exhibit different pathogenesis and characteristics [19].

The use of intraperitoneal injection in administering the extract in the present study was somewhat different from most of the similar studies. This route of administration is commonly used in small animals like mice and rats but rarely used in larger ones. Herein, this technique was used since the intravenous administration might not be feasible due to the high volume of administration and the characteristics of the extract. In addition, despite this method is parenteral access, the pharmacokinetics of the injected substance is considered comparable with the oral route of administration [20]. Yet, the use of this route might have influenced the degree of the blood pressure lowering effect of the extract and the doses as well. When compared with a previous study by Hasimun et al. [10] who administered the extract orally, the present study used larger doses with a comparable extent of the effect. Interestingly, one clear similarity between these two studies is that the best effect was shown by the smallest dose.

The antioxidant properties of E. americana have also gained interest alongside with its mostly reported antimicrobial activity. The antioxidant capacity of the plant is likely associated with the high content of naphthoquinones, one of the major compounds reported from the plant [21]. Although the present study did not evaluate the antioxidant capacity of the plant nor its correlation to the blood pressure lowering effect, it has been well recognized that antioxidants may be beneficial in reducing the high blood pressure. Some popular studies have proposed the antihypertensive effect of well-known antioxidants. These include those from vitamin $\mathrm{C}$ and $\mathrm{E}$ $[22,23]$ and tempol [24,25]. This perspective indicates that the future development of blood pressure lowering agent from E. americana is somewhat promising.

\section{Conclusion}

The study concludes that the extract of Eleutherine americana Merr. exhibits an antihypertensive activity which lowers the systolic, diastolic, and mean arterial pressure of hypertensive rats induced by prednisone and salt. The best effect of the extract is demonstrated by the dose of $100 \mathrm{mg} / \mathrm{kg}$, which is not significantly different to captopril. Meanwhile, this dose increases the heart rate higher than other doses of the extract. In conclusion, the study suggests that E. americana is potential for further development as a blood pressure lowering agent.

\section{Acknowledgment}

The authors gratefully acknowledge the Faculty of Pharmacy, Andalas University, Indonesia for the financial support of the present study under the scheme of DIPA 2018 (Contract No. 19/UN.16.10/DPPKM/ FFARMASI/2018).

\section{References}

[1]. WHO. WHO Traditional Medicine Strategy 2014-2023. World Health Organization (WHO). 2013. 1-76 p.

[2]. Carmona F, Pereira AMS. Herbal medicines: Old and new concepts, truths and misunderstandings. Brazilian J Pharmacogn. 2013;23(2):379-85.

[3]. Koehn FE, Carter GT. The evolving role of natural products in drug discovery. Nat Rev Drug Discov. 2005;4(3):206-20.

[4]. Kuntorini EM, Nugroho LH. Structural development and bioactive content of red bulb plant (Eleutherine americana); a traditional medicines for local Kalimantan people. Biodiversitas, J Biol Divers. 2010;11(2):102-6.

[5]. Han A-R, Min H-Y, Nam J-W, Lee N-Y, Wiryawan A, Suprapto W, et al. Identification of a new naphthalene and its derivatives from the bulb of Eleutherine americana with inhibitory activity on lipopolysaccharide-induced nitric oxide production. Chem Pharm Bull. 2008;56(9):1314-6.

[6]. Xu J, Qiu F, Duan W, Qu G, Wang N, Yao X. New bioactive constituents from eleutherine americana. Front Chem China. 2006;1(3):320-3.

[7]. InsanuM, KusmardiyaniS, Hartati R. RecentStudies on Phytochemicals and Pharmacological Effects of Eleutherine Americana Merr. Procedia Chem. 2014;13:221-8.

[8]. Zhengxiong C, Huizhu H, Chengrui W, Yuhui L, Jianmi D, Sankawa U, et al. Hongconin, a New Naphtalene Derivative from Hong-Cong, the Rhizome of Eleutherine americana Merr. et Heyne (Iridaceae). Chem Pharm Bull. 1986;34(7):2743-6.

[9]. Komura H, Mizukawa K, Minakata H, Huang H, Qin G, Xu R. New anthraquinones from Eleutherine americana. Chem Pharm Bull. 1983;31(11):4206-8.

[10]. Hasimun P, Zakaria H, Susilawati E, Wardiono JD. Antihypertensive activity ethanolic extract of bulb Eleutherine americana Merr on fructose-induced hypertension rats. Int J Pharm Pharm Sci. 2017;9(8):25-8.

[11]. Yuliandra Y, Armenia A, Arifin H. Antihypertensive and antioxidant activity of Cassytha filiformis L.: A correlative study. Asian Pac J Trop Biomed. 2017;7(7):614-8.

[12]. Armenia N, Gustinanda D, Salasa AN, Yuliandra Y. Acute and delayed toxicity study of Cassytha filiformis defatted ethanolic extract. World J Pharm Pharm Sci. 2015;4(10):155-62.

[13]. Brzenzinski W. Blood Pressure. In: Walker H, Hall W, Hurst J, editors. Clinical Methods: The History, Physical, and Laboratory Examinations. 3rd Ed. Boston: Butterworth Publishers; 1990. p. 95-7.

[14]. Armenia N, Alen Y, Ismed F, Yuliandra Y, Ananda R, Fitria F. Blood sugar lowering effectiveness of Cassytha filiformis fractions on diabetic mice. Res J Pharm Biol Chem Sci. 2016;7(6):1142-7.

[15]. Armenia A, Yuliandra Y, Sattar MZA. Comparative effectiveness of defatted hypotensive crude extract, ethyl acetate and butanolic fractions of Cassytha filiformis L. on different models of hypertensive rats. World J Pharm Pharm Sci. 2014;3(12):200-8.

[16]. Plehm R, Barbosa ME, Bader M. Animal models for hypertension/ blood pressure recording. Methods Mol Med. 2006;129:115-26. 
[17]. Parasuraman S, Raveendran R. Measurement of invasive blood pressure in rats. J Pharmacol Pharmacother. 2012;3(2):172-7.

[18]. Badyal DK, Lata H, Dadhich AP. Animal Models of Hypertension and Effect of Drugs. Indian J Pharmacol. 2003;35:349-62.

[19]. Giles TD, Materson BJ, Cohn JN, Kostis JB. Definition and classification of hypertension: An update. J Clin Hypertens. 2009;11(11):611-4.

[20]. Turner P V, Brabb T, Pekow C, Vasbinder M a. Administration of substances to laboratory animals: routes of administration and factors to consider. J Am Assoc Lab Anim Sci. 2011;50(5):600-13.

[21]. Mahabusarakam W, Hemtasin C, Chakthong S, Voravuthikunchai S, Olawumi I. Naphthoquinones, Anthraquinones and Naphthalene Derivatives from the Bulbs of Eleutherine americana. Planta Med. 2010;76(4):345-9.
[22]. Manning RD, Tian N, Meng S. Oxidative stress and antioxidant treatment in hypertension and the associated renal damage. Am J Nephrol. 2005;25(4):311-7.

[23]. Riccioni G, Bucciarelli T, Mancini B, Di llio C, Capra V, D'Orazio N. The role of the antioxidant vitamin supplementation in the prevention of cardiovascular diseases. Expert Opin Investig Drugs. 2007;16(1):2532.

[24]. Wilcox CS, Pearlman A. Chemistry and antihypertensive effects of tempol and other nitroxides. Pharmacol Rev. 2008;60(4):418-69.

[25]. Marañon RO, Juncos LA, Joo Turoni C, Karbiner S, Romero D, Peral De Bruno M. Tempol blunts afferent arteriolar remodeling in chronic nitric oxide-deficient hypertension without normalizing blood pressure. Clin Exp Hypertens. 2014;36(3):132-9.

Copyright ( 2018 The author(s). You are free to share (copy and redistribute the material in any medium or format) and adapt (remix, transform, and build upon the changes were made. You may do so in any reasonable manner, but not in any way that suggests the licensor endorses you or your use; ShareAlike - If you remix,
transform, or build upon the material, you must distribute your contributions under the same license as the original (https://creativecommons.org/licenses/by-sa/4.0/) 